\title{
Os condicionantes de saúde na legislação vigente sobre licenciamento ambiental
}

The health determinants in the current legislation on environmental licensing

\section{Flávia Ataíde França Teles ${ }^{1}$, Lilian Rose Lemos Rocha ${ }^{2}$}

Resumo: Os empreendimentos sujeitos ao licenciamento ambiental trazem consequências não só ao meio ambiente, mas também à saúde das populações vizinhas. $O$ presente artigo tem como objetivo analisar como os condicionantes de saúde são tratados pelas leis federais e normas infralegais vigentes sobre o tema. A metodologia consistiu na pesquisa bibliográfica por meio de análise de conteúdo e estudo de caso, sendo esta última feita em processo de licenciamento ambiental realizado pelo IBAMA, referente ao empreendimento para aproveitamento hidrelétrico do complexo do Rio Madeira. Como resultados, observouse que não há uma inserção sistemática dos condicionantes de saúde nos processos de licenciamento ambiental, o que torna necessária uma revisão e sistematização das normas referentes com uma visão interdisciplinar para melhor gerenciamento e mitigação dos impactos à saúde decorrentes de grandes empreendimentos.

Palavras-chave: Licenciamento Ambiental; Saúde; Legislação Ambiental.

\begin{abstract}
The enterprises subject to environmental licensing bring consequences not only for the environment but also to the health of neighboring populations. This article aims to analyze how the determinants of health are addressed by federal laws and regulatory provisions on the subject. The methodology consisted of bibliographical search through content analysis and case study, the latter being made in the environmental licensing process conducted by IBAMA, for the hydroelectric development of the Madeira River complex. As a result, it was observed that there was no systematic inclusion of health conditions in the environmental licensing process, which makes it necessary a review and systematization of standards related with an interdisciplinary vision for better management and mitigation of the health impacts resulting from large enterprises.
\end{abstract}

Keywords: Environmental Licensing; Health; Environmental.

Resumen: Los proyectos sujetos a licenciamiento ambiental traen consecuencias no sólo para el medio ambiente, sino también a la salud de las poblaciones vecinas. Este artículo tiene como objetivo analizar cómo los determinantes de la salud son abordados por las leyes federales y las disposiciones reglamentarias sobre la materia. La metodología consistió en la búsqueda bibliográfica a través de análisis de contenido y estudio de caso, siendo este último hecho en el proceso de licenciamiento ambiental llevado a cabo por el IBAMA, en referencia a aventurarse al complejo hidroeléctrico en el "Rio Madeira". Como resultado, se observó que no existía la integración sistemática de las condiciones de salud

\footnotetext{
${ }^{1}$ Especialista em Gestão Pública Ambiental pela Universidade de Brasília, Analista Ambiental do Ministério do Meio Ambiente. Brasília. Brasil. E-mail: flaviafteles@yahoo.com.br

${ }^{2}$ Mestre em Políticas Públicas e Desenvolvimento Sustentável - Universidade de Brasília. Brasília. Brasil.

E-mail: lilian.rocha@uniceub.br
} 
en el proceso de licenciamiento ambiental, lo que hizo necesaria una revisión y sistematización de las normas relativas a un mejor enfoque interdisciplinario para gestionar y mitigar los impactos en la salud derivados de los grandes emprendimientos.

Palabras-Ilave: Licenciamiento Ambiental; Salud; Legislación Ambiental.

\section{Introdução}

As crescentes exigências e pressões da sociedade em relação à preservação ambiental impuseram um desafio às empresas: serem competitivas e sustentáveis ao mesmo tempo (BARBOSA et al., 2010). Em nosso país, os impactos da implantação de projetos de desenvolvimento potencialmente poluidores é preocupação da legislação. Antes mesmo da Constituição Federal de 1988, o licenciamento ambiental foi implementado como instrumento da Lei n. ${ }^{\circ}$ 6.938, de 31 de agosto de 1981, que instituiu a Política Nacional do Meio Ambiente (PNMA). Posteriormente, a Carta Magna reforçou a ideia de que a defesa do meio ambiente pelo Poder Público é um dever constitucional ao instituir, em seu art. 225, $\S 1^{\circ}$, inciso IV, a obrigatoriedade da realização de estudo prévio de impacto ambiental para instalação de obra ou atividade potencialmente causadora de significativa degradação do meio ambiente.

Assim, as normas referentes ao licenciamento ambiental, como a já citada PNMA e a Resolução CONAMA no 01/86, que dispõe sobre os critérios básicos e as diretrizes da avaliação ambiental, apontam a saúde como fator a ser observado no processo. No entanto, a negligência das questões relativas à saúde no processo de licenciamento de grandes projetos é evidente, e a avaliação multidisciplinar de projetos de desenvolvimento, considerando saúde e meio ambiente, é incipiente. Neste contexto, o setor saúde vem buscando oportunidades de participar do processo (SILVEIRA; ARAÚJO NETO, 2013).

O que se verifica nos processos de licenciamento ambiental de grandes empreendimentos, no âmbito do Governo Federal brasileiro, são muitas injustiças ambientais. Como exemplo, os casos das hidrelétricas, que ocupam grandes extensões territoriais, afetam os segmentos mais vulneráveis, e geram custos pelos impactos socioambientais que causam a esses grupos. Entre outras externalidades observadas como consequência dos grandes empreendimentos, verifica-se o aumento dos gastos com os serviços no sistema de saúde, razão pela qual deve haver instrumentos que induzam a inclusão destes custos nos projetos, evitando assim que recaiam sobre as populações (SILVEIRA; ARAÚJO NETO, 2013). 
Tais instrumentos são fundamentais para que se proponha um processo produtivo sustentável, baseado numa análise anterior à construção do empreendimento que considere padrões ambientais, de segurança e de saúde, de modo a se estabelecerem as modificações necessárias para evitar efeitos negativos. Isso exige a integração das políticas sociais, econômicas e ambientais com vistas à implementação de ações voltadas à sustentabilidade (SILVEIRA et al., 2011).

A participação do setor saúde no processo de licenciamento ambiental se dá como ato discricionário do IBAMA, nos termos da Resolução do CONAMA nº 237/97 (art. 4º, $\left.\S 1^{\circ}\right)$. O primeiro marco legal a deixar clara a inserção dos condicionantes de saúde no licenciamento ambiental foi a Resolução CONAMA n² 286/01, que dispõe sobre o processo de licenciamento de empreendimentos nas regiões endêmicas de malária. No entanto, na implantação de empreendimentos em outras regiões, esses condicionantes não são considerados (SILVEIRA; ARAÚJO NETO, 2013).

Outro fator que contribui para esse quadro é a inexistência de uma ferramenta específica de avaliação de impacto sobre a saúde para os processos de licenciamento ambiental. Quando solicitado, o setor saúde insere suas recomendações em um formato padronizado; porém, faz-se necessária a definição de critérios pelo IBAMA para solicitação de posicionamento técnico ao setor (SILVEIRA; ARAÚJO NETO, 2013).

Assim, embora o referencial normativo explicite a importância da participação do setor saúde, não há legislação específica que o exija, com exceção das áreas endêmicas de malária. Há que se prever mecanismos institucionais e técnicos para assegurar, de forma sustentável e efetiva, a participação do setor saúde como condicionante para o licenciamento ambiental de grandes empreendimentos (SILVEIRA; ARAÚJO NETO, 2013). O licenciamento ambiental tem seus procedimentos tratados, principalmente, em normas infralegais, expedidas pelo Conselho Nacional de Meio Ambiente (CONAMA), e a legislação federal trata o tema dentro do arcabouço do Direito Ambiental. O objetivo do artigo é analisar como os condicionantes de saúde são tratados pelas leis federais e normas infralegais vigentes sobre licenciamento ambiental.

A PNMA, estabelecida pela Lei $n .{ }^{\circ}$ 6.938, de 1981, traz a definição de poluição como a degradação da qualidade ambiental resultante de atividades que direta ou indiretamente, entre outros fatores, prejudiquem a saúde, a segurança e o bem-estar da população (art. 30,"a”). Dentre os objetivos da PNMA está a „compatibilização do desenvol- 
vimento econômico-social com a preservação da qualidade do meio ambiente e do equilíbrio ecológico,,(art. $\left.4^{\circ}, \mathrm{I}\right)$.

Entre os diversos instrumentos da PNMA, a Lei relaciona a avaliação de impactos ambientais e o licenciamento e a revisão de atividades efetiva ou potencialmente poluidoras (art. 9ํㅗ III e IV).

O Decreto $\mathrm{n}^{0}$ 99.274, de 6 de junho de 1990, que regulamenta a referida lei, estabelece que o CONAMA é o órgão competente para estabelecer normas e critérios para o licenciamento ambiental. Compete ainda ao Conselho determinar a realização de estudos das alternativas e das possíveis consequências ambientais de projetos públicos ou privados, requisitando aos outros órgãos as informações indispensáveis para apreciação dos estudos de impacto ambiental, e respectivos relatórios (art. 7ํㅜㄹ inciso II).

O Estudo de Impacto Ambiental (EIA) será realizado por técnicos habilitados e constituirá o Relatório de Impacto Ambiental (RIMA), que será feito e custeado pelo proponente do projeto e a que se dará a devida publicidade (art. 17, §2).

Outra norma federal, a Lei n. 11.516, de 28 de agosto de 2007, faz referência à incumbência de outros órgãos públicos da elaboração de parecer em processo visando à emissão de licença ambiental (art. 14). Esta atuação dos órgãos e entidades da Administração Pública Federal envolvidos no licenciamento veio a ser regulamentada pela Portaria Interministerial n. $\stackrel{0}{419}$, de 23 de outubro de 2011, que relaciona como órgãos passíveis desse envolvimento a Fundação Nacional do Índio (FUNAI), a Fundação Cultural Palmares (FCP), o Instituto do Patrimônio Histórico e Artístico Nacional (IPHAN) e o Ministério da Saúde.

Cumpre observar que tramita na Câmara dos Deputados Projeto de Decreto Legislativo de autoria do Deputado Nilson Leitão, o PDC n 1465/2014, visando sustar a aplicação da Portaria Interministerial n.4 419, de 2011, por alegada extrapolação de competência. Na justificativa da proposta, o autor analisa que a norma tem efeito "único e exclusivo de prejudicar o devido andamento legal do processo, atrasá-lo e, principalmente, onerar o empreendedor responsável pelo projeto". Entende que a interferência dos órgãos envolvidos coloca em risco a viabilidade do projeto de licenciamento ambiental, e busca apenas retirar a competência do IBAMA em decidir sobre a concessão das licenças.

A participação do Ministério da Saúde nos processos se dará em caso de licenciamento em regiões endêmicas de malária, aí compreendidos os municípios localizados em áreas de risco ou endêmicas, devendo, nesses casos, o IBAMA solicitar ao 
empreendedor, já no início do procedimento de licenciamento ambiental, informações sobre possíveis interferências. Desde 2005, o Departamento de Vigilância em Saúde Ambiental e Saúde do Trabalhador (DSAST) vem atuando nos processos de licenciamento ambiental de grandes empreendimentos para inserir as questões específicas de saúde e subsidiar o órgão ambiental na emissão das licenças (SILVEIRA et al., 2011). No Termo de Referência do estudo ambiental exigido pelo IBAMA já deverão constar as exigências de informações ou estudos específicos sobre $o$ assunto.

A despeito disso, ao analisar os relatórios ambientais de 21 empreendimentos nacionais de produção de petróleo licenciados no período de 1ํ de janeiro de 2004 a 31 de outubro de 2009, Barbosa et al. (2010) constatou a inexistência de evidências da incorporação de aspectos de saúde na maioria dos respectivos EIA. Concluiu em sua pesquisa que nenhum dos EIA/RIMA avaliou os impactos do empreendimento sobre os principais indicadores públicos de saúde, como morbidade, mortalidade e atendimento ambulatorial e hospitalar; e em nenhum dos estudos analisados foi considerada a identificação de medidas mitigadoras referentes aos impactos relacionados à infraestrutura e aos serviços de saúde, e, especificamente aquelas referentes às populações mais vulneráveis e que apresentam risco à saúde humana.

Observou ainda que nenhum dos estudos analisados explicitou a sistemática de acompanhamento e monitoramento das ações governamentais de saúde voltadas ao controle dos impactos do empreendimento sobre os trabalhadores e as comunidades das áreas de influência, bem como aquelas adotadas pelo empreendimento direcionadas às comunidades.

Empreendimentos como assentamentos de reforma agrária, esgotamento sanitário, extração mineral, geração de energia elétrica etc., também tem resoluções específicas sobre seus processos de licenciamento. Assim, percebe-se que o assunto é tratado de forma esparsa no ordenamento jurídico, em leis e decretos federais, resoluções e portarias, algumas específicas a determinado assunto. Isso gera dificuldades tanto ao empreendedor, em observar todas as normas de seu interesse, quanto à fiscalização, seja do órgão competente do Sistema Nacional de Meio Ambiente (SISNAMA), seja do Ministério Público e da própria sociedade; e gera, ainda, discussões acerca da legitimidade dessas normas, uma vez que a competência para normatizar o assunto é conferida pela 
PNMA ao CONAMA, e, no entanto, portarias interministeriais do Ministério da Saúde e mesmo do Ministério do Meio Ambiente trazem novas regras ao tema.

\section{Meio ambiente, Saúde e Desenvolvimento}

O processo produtivo causa, obrigatoriamente, transformações na natureza, que irão refletir no modo de vida das pessoas, na sua saúde e na disponibilidade dos recursos. Tais transformações podem implicar, ainda, riscos, e nesse processo devem ser sempre previstas possibilidades e ações de intervenção concreta para mitigá-los, o que requer uma abordagem multi, inter ou transdisciplinar, envolvendo diversas áreas de conhecimento para o desenvolvimento dos estudos necessários para avaliação dos efeitos da exposição aos poluentes ambientais (TAMBELLINI; CÂMARA, 1998).

As situações de risco ambiental que interferem na saúde das populações são complexas e exigem, além dos estudos, um trabalho integrado das diversas instituições envolvidas (TAMBELLINI; CÂMARA, 1998) tanto na elaboração de políticas públicas quanto na sua execução, referentes à matéria de saúde e de meio ambiente. O processo produtivo traz consigo uma ampla gama de riscos ambientais, relacionados a equipamentos e tecnologias que, ao longo do tempo, vão influir no perfil de morbimortalidade local e processos de adoecimento diversos (RIGOTTO, 2009).

A proliferação de doenças ou intoxicações pelo uso de agrotóxicos e mercúrio, a poluição dos rios, alimentos contaminados, cidades desumanizadas, campos devastados, tudo isso vem constituindo grave problema de saúde pública (MILARÉ, 2009), além da sua relação inegável com a matéria ambiental. O estabelecimento de conexões entre políticas de saúde e ambientais que avaliem a necessidade de preservação dos recursos naturais e a qualidade de vida das populações inseridas nos espaços socioambientais é essencial para a sustentabilidade. Nesse sentido, o licenciamento ambiental, como instrumento da PNMA, pode ser utilizado como indutor de políticas de saúde favoráveis ao desenvolvimento de projetos ecologicamente sustentáveis (SILVEIRA et al., 2011).

A Constituição Federal de 1988 inicia no art. 193 o Título VIII, da Ordem Social, que tem como base o primado do trabalho e como objetivo o bem-estar e a justiça social. Neste mesmo título se encontram o ordenamento sobre a saúde (arts. 196 a 200), aí incluído o Sistema Único de Saúde, e sobre o meio ambiente (art. 225). Tanto a saúde quanto o meio ambiente equilibrado são tratados como direitos e incumbe ao Poder Público o dever de 
garantir a todos o acesso à saúde e a defesa e preservação do meio ambiente. Entre as competências atribuídas ao SUS está a colaboração na proteção do meio ambiente (art. 200, VIII).

Cumpre fazer aqui uma relação entre o conceito constitucional de meio ambiente e o conceito de saúde dado pela Organização Mundial da Saúde (OMS). O primeiro é visto pela Carta Magna como „bem de uso comum do povo e essencial à sadia qualidade de vida, o segundo definido pela OMS como o estado do mais completo bem-estar físico, mental e social e não apenas a ausência de enfermidade". Ambos tratam de conceitos bem subjetivos, como qualidade de vida e bem-estar, e, fazendo o primeiro conceito expressa menção ao segundo, inegavelmente remetem um ao outro e se complementam.

A Ordem Econômica e Financeira, tratada no Título VII da Constituição de 1988, com suas características e valores específicos, subordina-se à Ordem Social, uma vez que o fim social constitui a grande meta de toda ação do Poder Público e da sociedade. O crescimento ou o desenvolvimento socioeconômico deve portar-se como um instrumento eficaz para subsidiar o objetivo social maior, não podendo as atividades econômicas gerar problemas que afetem a qualidade ambiental e impeçam o seu pleno atingimento (MILARÉ, 2009). Um plano de desenvolvimento não pode estar dissociado do anseio global e nacional do desenvolvimento sustentável, mas sim ancorado no tripé desenvolvimento econômico, justiça social e manutenção da qualidade dos ecossistemas (BARBOSA et al., 2010).

Nesse contexto, e considerando a tríade saúde-ambiente-desenvolvimento, é que devem ser analisados os fundamentos legais da avaliação de impactos ambientais e do licenciamento de atividades efetiva ou potencialmente poluidoras, definidos pela Lei $\mathrm{n} .{ }^{\circ}$ 6.938, de 1981, como instrumentos da PNMA, observando o tratamento que a legislação referente dispensa ao processo, aí incluídas as normas infra legais, dá aos condicionantes de saúde e o quanto este fator interfere no desfecho do processo.

\section{Metodologia}

A presente pesquisa abrange dois aspectos; a pesquisa bibliográfica, por meio de análise de conteúdo; e, o estudo de caso, com abordagem qualitativa. A revisão da literatura acerca do tema proposto foi realizada mediante consulta à base de dados eletrônicos do Scielo e Portal de Pesquisa da Biblioteca Virtual em Saúde (BVS). 
Para o levantamento de dados foram utilizadas as palavras chaves: "licenciamento ambiental", „avaliação de impactos ambientais e saúde", isoladamente ou por associação entre elas, no sentido de selecionar os documentos publicados de interesse do estudo. Os critérios de inclusão para seleção dos documentos foram: artigos nacionais, publicados no idioma português, cuja abordagem referenciasse os condicionantes de saúde no licenciamento ambiental.

A partir da leitura dos documentos encontrados, foram eleitos cinco para a análise, os quais tinham uma abordagem teórica satisfatória para atingir os objetivos desse trabalho.

A documentação definida para estudo foi buscada na página institucional do Instituto Brasileiro do Meio Ambiente e dos Recursos Naturais Renováveis (IBAMA), no Sistema Informatizado de Licenciamento Ambiental Federal (SISLIC), referente ao empreendimento denominado Complexo do Rio Madeira (UHE Jirau), que tem por objeto os Aproveitamentos Hidrelétricos no rio Madeira, AHE Santo Antônio e AHE Jirau e Sistema de Transmissão Associado, disponível em www.ibama.gov.br/licenciamento/index.php; em Consulta/Empreendimentos, informado como Argumento para Pesquisa o Número do Processo: 02001.003771/2003-25.

\section{Análise da documentação do Processo de Licenciamento n. 02001.003771/2003-25}

O processo citado no subtítulo é referente ao empreendimento denominado complexo do Rio Madeira - Usina Hidrelétrica Jirau, que tem por objeto os aproveitamentos hidrelétricos nos rios Madeira, Santo Antônio e Jirau e sistema de transmissão associado. Inclui, ainda, o Termo de referência para elaboração do estudo de Impacto Ambiental e o respectivo Relatório de Impacto Ambiental - Setembro/2004.

Iniciou-se a análise da documentação referente ao processo de licenciamento para o empreendimento pelo Termo de Referência (TR), para elaboração do Estudo de Impacto Ambiental e o respectivo Relatório de Impacto Ambiental (EIA/RIMA).

No que diz respeito ao meio socioeconômico, o TR demanda uma pesquisa a partir de dados primários e secundários, entrevistas qualificadas, onde deverão constar, entre outros aspectos, uso e ocupação do solo, caracterização socioeconômica das comunidades afetadas e organização social e serviços públicos 
. Neste último aspecto, no que se refere à saúde pública, exige a análise dos serviços de saúde oferecidos à população; saneamento básico e abastecimento de água; identificação de endemias e seus focos, apresentando dados qualitativos e quantitativos da evolução dos casos e avaliando a influência do empreendimento nestas ocorrências; e identificação dos serviços públicos que devem sofrer os maiores impactos com o empreendimento.

O EIA deverá ainda analisar a infraestrutura existente em saúde, apresentando indicadores de morbidade, mortalidade, além de planos, programas e projetos públicos e privados incidentes na área de influência.

Ressalta que a empresa deverá requerer os Pareceres da Fundação Palmares, IPHAN, FUNASA e FUNAI, quando for o caso, numa clara menção à Portaria Interministerial no 419, de 2011.

No item „Regulamentação aplicável ao licenciamento", é interessante observar que o TR cita as três Resoluções do CONAMA que tratam da matéria: a Resolução no 001/86, que situa as usinas de geração de energia elétrica deste porte entre obras e empreendimentos sujeitos à avaliação de impacto ambiental; a Resolução no 06/87, que correlaciona a requisição e obtenção de Licença Prévia à apresentação e aprovação do EIA/RIMA; e a Resolução no 237/97, que define as competências e indica as fases do processo de licenciamento.

Além dessas normas específicas, menciona ainda 28 diplomas legais, dos quais apenas um faz referência expressa à saúde: o Decreto Federal ํำ1.141, de 5 de maio de $1994^{3}$, que dispõe sobre ações de proteção ambiental, saúde e apoio de comunidades indígenas.

A Avaliação do Impacto Ambiental (AIA) deverá levar em consideração os diversos fatores e seus tempos de incidência (abrangência temporal) nas fases de implantação e operação do empreendimento. Deverão ser descritas as mais significativas mudanças provocadas pelo empreendimento em relação às questões sociais (nível de emprego,

\footnotetext{
${ }^{3}$ Este Decreto foi revogado pelo Decreto n. ${ }^{\circ} 7.747$, de 5 de junho de 2012, que Institui a Política Nacional de Gestão Territorial e Ambiental de Terras Indígenas - PNGATI, e dá outras providências.
} 
problema de prostituição, violência urbana, doenças, uso de entorpecentes, entre outros) e de infraestrutura (saneamento básico, efluentes líquidos, emissões atmosféricas, resíduos sólidos, ruídos e tráfego).

\section{Relatório de Impacto Ambiental - Maio/2005}

O segundo documento analisado foi o RIMA, apresentado pelo consórcio das empresas Furnas Centrais Elétricas S.A. e Construtora Norberto Odebrecht S.A., com data de maio de 2005. Entre os especialistas responsáveis pelo EIA em seus aspectos sociais, estavam uma arqueóloga, um médico e uma terceira profissional. Os estudos sobre aspectos socioeconômicos ainda contaram com a participação da Universidade Federal de Rondônia (UNIR). Faz-se breve análise dos aspectos relacionados à saúde abordados no documento.

$\mathrm{Na}$ análise das habitações, verificou-se que a maioria das casas nas áreas rurais tem acesso à água por poço ou nascente, sem nenhum tratamento, e grande parte não dispõe de instalações sanitárias. Nas áreas urbanas, à exceção da cidade de Porto Velho, não há redes de esgotos servindo à população ribeirinha do Madeira.

Sobre a atenção à saúde, em toda a área observada, os serviços são prestados por postos de saúde, onde equipes do Programa de Saúde da Família (PSF) fazem atendimentos nos fins de semana. Qualquer recurso além do atendimento ambulatorial deve ser buscado em Porto Velho.

O estado de saúde da população às margens do rio Madeira foi classificado como satisfatório, considerando raros os casos de desnutrição ou queixas clínicas. Já as verminoses são frequentes, e uma parcela significativa dessa população terá tido em sua vida, pelo menos, dois episódios de malária. Menciona epidemias de dengue, mas poucos casos ativos de leishmaniose.

O RIMA afirma que, para evitar o risco de sobrecarga aos hospitais públicos, o empreendedor providenciará o atendimento médico dos trabalhadores nos canteiros e convênios de assistência à saúde para este grupo. Caso seja necessário, apoiará o município nas questões assistenciais.

Sobre as ações para corrigir ou compensar os impactos negativos dos Projetos, cita a criação do Programa de Saúde Pública, dividido em dois conjuntos de ações: o primeiro destinado à assistência à saúde pública; o segundo, à vigilância epidemiológica e de 
vetores. Tais medidas têm como alvo os grupos humanos expostos aos efeitos dos empreendimentos, representados pela população residente no município de Porto Velho, trabalhadores nas obras e seus familiares e população atraída pelas oportunidades de trabalho.

O conjunto de atividades relacionadas à vigilância epidemiológica e de vetores de doenças será ativado por meio de dois subprogramas integrados: o de Monitoramento e Controle de Vetores e o de Monitoramento e Controle de Doenças. Para o cumprimento das finalidades previstas nesse Programa, será criado o Centro de Vigilância em Saúde, ligado à Secretaria Municipal de Porto Velho.

Foi realizada a checagem de atendimento do EIA/RIMA ao Termo de Referência em novembro de 2005, seis meses depois de apresentado ao IBAMA pelo empreendedor. A despeito de terem sido verificadas algumas deficiências, não foram consideradas pelo órgão avaliador fatores impeditivos para dar seguimento ao processo e tornar público o recebimento do documento. Feitas algumas diligências, foi então publicado o edital relacionando os locais para consulta do EIA/RIMA por qualquer interessado, em 24 de outubro de 2006.

\section{Relatório de análise do conteúdo do EIA/RIMA - Ministério Público do Estado de Rondônia - Dezembro/2006}

O terceiro documento analisado foi a „Análise do Conteúdo dos Estudos de Impacto Ambiental (EIA) e do Relatório de Impacto sobre o Meio Ambiente (RIMA) dos Aproveitamentos Hidrelétricos de Santo Antonio e Jirau, no Rio Madeira, Estado de Rondônia", realizada pela Companhia Brasileira de Projetos e Empreendimentos (COBRAPE), por solicitação do Ministério Público do Estado de Rondônia, para ampará-lo na caracterização e avaliação dos impactos ambientais, das medidas e ações mitigadoras e compensatórias previstas com a construção do Complexo Hidrelétrico Rio Madeira.

Divide-se o estudo em três partes: a primeira aborda uma visão sistêmica e uma análise crítica do EIA/RIMA, propondo, na sequência, um Plano Integrado de Compensação Regional para os impactos dos Aproveitamentos Hidrelétricos de Santo Antônio e Jirau e apresentando uma Agenda de Viabilização Socioeconômica, Ambiental e Institucional dos empreendimentos. A segunda parte apresenta os pareceres técnicos dos especialistas setoriais, e a terceira traz os anexos. No item Políticas Públicas Sociais, 
analisam-se os temas tratados no EIA/RIMA relativos à educação, saúde, segurança pública e assistência social. Entende o avaliador que o diagnóstico realizado no EIA é bastante completo com respeito à área de saúde, analisando desde a estrutura da prestação dos serviços, até o perfil de morbimortalidade, a situação das endemias, doenças infecciosas, vetores e demais temas relevantes, demonstrando problemas e demandas reprimidas. Foram utilizados dados do Sistema Federal de Informações (DATASUS) além de dados e estudos locais, como o de malária, leishmaniose, dengue, febre amarela, doença de chagas e oncocercose.

De modo geral, o EIA demonstra que o estado de saúde da população é bom, tendo a malária e as verminoses maior frequência na região do Jirau e do Santo Antônio, respectivamente. Já no município de Porto Velho, o EIA destacou os elevados índices de morbidade, relacionados, principalmente, às deficiências nas ações de atenção básica, à carência de recursos financeiros e à falta de leitos hospitalares.

Este levantamento detectou, ainda, o problema de falta de médicos nos Centros de Saúde, a escassez de recursos para o Programa de Saúde da Família (PSF), e a falta de medicamentos da farmácia básica.

Destaca a falta de recursos humanos na Vigilância Sanitária Municipal de Porto Velho, e a escassez de pessoal e equipamentos para a Vigilância Epidemiológica. O EIA/RIMA propõe medidas de assistência à saúde pública, vigilância epidemiológica e vetorial e monitoramento e controle de vetores.

Os impactos e as propostas de mitigação previstos no EIA se organizaram da seguinte forma: alteração na dinâmica de vetores e na incidência de malária; aumento da incidência de outras doenças; e risco de acidentes com animais peçonhentos e com máquinas e veículos. Prevê diversas medidas específicas para cada classe de problemas.

A COBRAPE propõe uma Agenda de Viabilização Socioeconômica, Ambiental e Institucional dos Aproveitamentos Hidrelétricos de Santo Antônio e Jirau, para dar concretude às demandas constatadas associadas à viabilização dos empreendimentos. Essa agenda está dividida em três grandes blocos, quais sejam: ações institucionais, meio físico e biótico e meio socioeconômico.

Propõe o documento uma ampliação e inclusão de ações no Subprograma de Assistência à Saúde, no âmbito do Programa de Saúde Pública do EIA, com várias linhas de atuação em Ações de Atenção Básica, Ações de Média e Alta Complexidade, além de pesquisa de portadores assintomáticos da malária. 
$\mathrm{Na}$ segunda parte da análise apresentam-se os pareceres técnicos diversos. $\mathrm{O}$ primeiro trata dos Estudos Hidrobiogeoquímicos, com atenção específica à dinâmica do mercúrio. Neste caso, os especialistas concluíram que o estudo do EIA/RIMA prescinde de algumas informações sobre contaminação da população.

O parecer técnico sobre Entomologia concluiu que a área de construção do Aproveitamento Hidrelétrico do Jirau é de alto risco para malária, tanto em função da extensão e da densidade de ocorrência do vetor, como pelo elevado quadro da doença, não só na área do empreendimento, mas também nas áreas de influência. Verifica-se a necessidade da implementação de programas de vigilâncias entomológica e epidemiológica e de ampliação das estruturas de saúde para as ações de diagnóstico rápido. Destaca o monitoramento contínuo sobre os quadros de febres graves e, em relação à febre amarela, necessidade de ampliação das estratégias de vacinação. Quanto às filarioses, a vigilância maior será quando da admissão dos trabalhadores para a obra.

O parecer técnico sobre Planejamento Regional e Urbano alerta que deverão ser efetuadas análises sobre capacidade e área de influência dos equipamentos e das infraestruturas e serviços urbanos existentes, bem como verificadas as demandas geradas pelo crescimento populacional.

Por fim, o parecer técnico sobre Saúde Pública faz uma avaliação do processo de colonização do estado de Rondônia e do município de Porto Velho, e classifica a situação de equilíbrio da população residente frente ao meio socioambiental como "instabilíssimo".

O autor faz um aprofundado diagnóstico da situação de saúde e da assistência prestada à população em Porto Velho. Parte da análise dos recursos financeiros que são transferidos pelos governos federal e estadual, avalia os gastos municipais com a saúde no ano de 2005 e apresenta a estrutura atual da Secretaria Municipal de Saúde de Porto Velho (SEMUSA) com riqueza de detalhes. A avaliação dos recursos existentes para a cobertura de atenção básica converge com a do EIA/RIMA, e demonstra as insuficiências para atendimento às necessidades da população.

Aponta a falta de leitos hospitalares no município de Porto Velho e a solução proposta pelo programa de Assistência à Saúde da População definido no EIA para solucionar este problema. No tocante ao controle de vetores, observa que o EIA deixa evidente a importância das doenças transmitidas por insetos e faz especial destaque à malária, à dengue e à leishmaniose tegumentar. 
Avalia que a questão da malária é abordada de forma apropriada no EIA/RIMA, inclusive com relação aos portadores assintomáticos da doença.

Destaca o tratamento que o EIA/RIMA confere à vigilância em saúde, apontando a necessidade de fortalecer as estruturas existentes em Porto Velho e no estado de Rondônia e propondo programa específico de vigilância em saúde que deverá anteceder em um ano o início das obras.

Sobre a atenção à saúde dos trabalhadores contratados para as obras de construção das hidrelétricas, a avaliação do EIA/RIMA ressalta que é importante que não haja sobrecarga dos serviços públicos de saúde, desde o nível da atenção básica até as demandas por serviços especializados e de maior complexidade, além de internações hospitalares, que deverão ser atendidas por serviços conveniados ou contratados diretamente.

Considera positiva a postura do empreendedor de estabelecer uma parceria com o município no aperfeiçoamento de ações de saúde pública, mas avalia que é preciso definir melhor como esta parceria acontecerá. Nesta etapa do licenciamento, cabe ao empreendedor identificar os impactos que serão gerados e apontar o delineamento geral dos programas a serem implantados para mitigar/compensar esses impactos. Os limites da parceria são dados pela legislação ambiental, que atribui ao empreendedor a responsabilidade pela reparação dos impactos causados pelas obras.

Conclui o parecer por uma salutar preocupação do EIA/RIMA em definir, previamente, os impactos decorrentes da construção dessas hidrelétricas sobre o meio ambiente biótico e abiótico. Diante dos impactos previstos, afirma que é necessário haver uma ação antecipada também para a adequação da infraestrutura de atendimento à saúde. No cronograma de implantação das obras, as ações do programa de assistência à saúde deverão ser colocadas de forma a garantir que não haja colapso no sistema de saúde local em nenhuma das etapas da construção. 


\section{Outros documentos e conclusão do Processo}

Em 23 de agosto de 2006, foi enviado à Superintendência de Gestão Ambiental de Furnas Centrais Elétricas S/A ofício solicitando a remessa do EIA/RIMA à Secretaria de Vigilância em Saúde (SVS/MS) para o atendimento ao preceituado na Resolução CONAMA n. ำ 286/2001, que dispõe sobre o licenciamento ambiental de empreendimentos nas regiões endêmicas de malária. Em setembro de 2006, a Coordenação-Geral do Programa Nacional de Controle da Malária respondeu ao IBAMA que, nos termos da Portaria n.ำ509/GM, de 6/4/2006, o Atestado de Aptidão Sanitária (AAS) é emitido após a publicação da Licença Prévia.

No entanto, no dia 15 de março de 2007, a SVS oficiou ao IBAMA informando que a referida norma havia sido substituída pela Portaria 47/2007/SVS/MS ${ }^{4}$, que definia que, nos casos de licenciamento enquadrados nas Resoluções CONAMA n 01/86 e nำ 237/97, a solicitação do Laudo de Avaliação do Potencial Malarígeno (LAPM) deveria ser feita antes da emissão da Licença Prévia, e o Atestado de Condição Sanitária (ATCS) deveria ser obtido anteriormente à emissão da Licença de Instalação pelo órgão ambiental.

Realizadas avaliações técnicas e outras demandas processuais normais ao processo, em maio de 2007 foram protocolados questionamentos a serem submetidos à empresa proponente e especialistas contratados, sobre três assuntos, sendo um deles a problemática da presença de mercúrio no rio Madeira, assunto de relevância ambiental e de saúde pública. Das seis questões elaboradas, uma era relativa, exclusivamente, à contaminação da população e outras se referiam à contaminação da água ou dos peixes, perpassando assim pelo tema da saúde.

Emitido memorando conclusivo acerca da viabilidade de emissão da Licença Prévia em julho de 2007, concluiu que, a princípio, a avaliação técnica do IBAMA foi pela insuficiência de informações quanto à magnitude dos impactos e os mecanismos de anulação, mitigação ou compensação, principalmente no que se referia, em questões de saúde, à remobilização do mercúrio e ao risco de chegar aos seres humanos, e à proliferação da malária, uma vez que as medidas propostas para o enfrentamento deste problema eram frágeis e ainda estava pendente o atestado de aptidão sanitária.

\footnotetext{
${ }^{4}$ Esta Portaria já não está em vigor; foi revogada pela Portaria n. 1 , de 13 de janeiro de 2014, que estabelece diretrizes, procedimentos, fluxos e competência para obtenção do Laudo de Avaliação do Potencial Malarígeno (LAPM) e do Atestado de Condição Sanitária (ATCS) de projetos de assentamento de reforma agrária e outros empreendimentos sujeitos ao licenciamento ambiental em áreas de risco ou endêmica para malária.
} 
Entretanto, depois de sistematizadas as informações, especialmente sobre o mercúrio, foram feitas diversas reuniões sobre o tema. Em junho de 2007, o Ministério do Meio Ambiente realizou reunião com representantes do IBAMA, Ministério da Saúde, Instituto Evandro Chagas e o Consórcio Furnas/Odebrecht, e concluiu-se que os riscos sobre o mercúrio não se caracterizariam como fatores de inviabilidade do empreendimento. No entanto, se estabeleceram recomendações para ações de monitoramento e medidas de controle, com programas de controle de exposição humana ao mercúrio, atenção à saúde, e educação ambiental e em saúde.

O IBAMA recomendou, ainda, a incorporação à equipe técnica responsável pela análise dos estudos ambientais de um profissional com especialização compatível com o mérito do tema, bem como a contratação de especialistas de notório saber; e ainda que fosse feita uma consulta formal ao setor de saúde.

Em 9 de julho de 2007, foi emitido pelo Diretor de Licenciamento do IBAMA Parecer Técnico Conclusivo opinando pela emissão da Licença Prévia.

Na situação do empreendimento, o processo consta como "Encerrado".

\section{Discussão}

Um modelo de desenvolvimento com atenção à sustentabilidade socioambiental já foi inserido na agenda global. Neste contexto, a saúde da população deve ser tratada de forma integrada aos fatores ambientais e às questões econômicas, considerando tanto os impactos provenientes das alterações como poluição ou degradação ao meio ambiente natural, como também aqueles ocasionados pela dinâmica populacional, que tem o potencial de alterar toda a sistemática de um território (BRASIL, 2014).

Desse modo, a complexidade dos problemas socioambientais conferem a necessidade de uma abordagem sistêmica, interdisciplinar e intersetorial para as questões do desenvolvimento, que permita apreender sua amplitude e as inter-relações causais entre os impactos ambientais e os respectivos efeitos à saúde humana. A responsabilidade para se promover saúde e qualidade de vida não cabe somente a um setor, mas deve ser firmada com ações multidisciplinares e apoiadas por políticas públicas que possibilitem adequada ação do setor saúde nas fases de elaboração dos projetos, implementação e monitoramento. 
Nesse contexto, a partir de um novo ciclo de desenvolvimento econômico-social no Brasil, o Governo Federal lançou, em 2007, o Plano de Aceleração do Crescimento (PAC), que incluía geração e transmissão de energia hidrelétrica, petróleo, gás natural e combustível renovável. Um plano dessa dimensão deve estar associado ao propósito do desenvolvimento sustentável, atendendo aos anseios de desenvolvimento econômico com justiça social e preservação ambiental. Os riscos ambientais inerentes ao processo produtivo devem ser considerados para se estabelecerem conexões entre políticas de saúde e ambientais, de modo a buscar-se a preservação dos recursos naturais e a qualidade de vida das populações afetadas, e o licenciamento ambiental pode ser um importante indutor dessas políticas.

Com a intensificação do PAC, o Ministério da Saúde passou a ter maior envolvimento como uma instituição interveniente nos processos de licenciamento ambiental e, atualmente, participa dos processos fazendo análise e requisição de estudos específicos à saúde e executando ações em regiões influenciadas por grandes empreendimentos. A participação do Ministério da Saúde no licenciamento tem acontecido sempre que solicitada pelo IBAMA e ocorre por meio da apreciação dos aspectos de saúde nos Termos de Referência e nos EIA/RIMA encaminhados pelo órgão ambiental (BRASIL, 2014).

A despeito de todo esse contexto, verificamos que há o entendimento, entre os próprios legisladores, de que esse tratamento interdisciplinar atrasaria e prejudicaria 0 processo, a exemplo do PDC nำ1.465/2011.

Percebe-se ainda a inexistência da incorporação de aspectos de saúde em grande parte dos EIA/RIMA, que não analisam os impactos do empreendimento sobre indicadores de saúde e não consideram medidas mitigadoras referentes aos impactos à estrutura e aos serviços de saúde.

No caso aqui analisado, do licenciamento ambiental da Hidrelétrica do Complexo do Rio Madeira - Usina Hidrelétrica Jirau, vê-se que os únicos mecanismos institucionais que garantem essa participação são a Resolução CONAMA 286/2001, que dispõe sobre o licenciamento de empreendimentos em regiões endêmicas de malária, e a Portaria SVS/MS no 1 , de 13 de janeiro de $2014^{5}$, que prevê como condicionantes para a licença prévia nesses mesmos casos a emissão pelo Ministério da Saúde de documentos como o

${ }^{5}$ Revogou a Portaria SVS/MS n. 47, de 29 de dezembro de 2006, que já tratava do assunto. 
Laudo de Avaliação do Potencial Malarígeno (LAPM) e o Atestado de Condição Sanitária (ATCS). Faz-se, assim, necessária uma maior articulação do setor saúde com o setor ambiental para regulamentação de normas ou resoluções que englobem os agravos e os riscos à saúde humana não só nessas áreas, mas em todo o território brasileiro.

\section{Considerações Finais}

Embora haja uma forte interface entre a saúde e as políticas ambientais, não se veem instrumentos jurídicos satisfatórios que estabeleçam a obrigatoriedade do setor saúde participar nos processos de licenciamento. Assim como a Resolução CONAMA no 01/86 faz referência à saúde na definição de impacto ambiental, a Resolução ํㅜ 237/97 dá ao órgão ambiental a prerrogativa de suspender ou cancelar uma licença expedida em caso de superveniência de graves riscos ambientais e de saúde (art. 19, III). Entretanto, na prática são exigidos estudos essencialmente sobre os aspectos ambientais.

Além disso, apesar da relevância dos impactos à saúde causados pelos empreendimentos passíveis de licenciamento por sua natureza efetiva ou potencialmente poluidora ou causadora de degradação ambiental, os órgãos ambientais responsáveis pelo processo de licenciamento não tem corpo técnico competente para analisar esses aspectos, vislumbrando-se a necessidade de estruturação sistemática da participação do setor saúde, o que só se dará por meio de normatização específica.

Conclui-se, desse modo, que, à exceção dos casos específicos de licenciamento de empreendimentos em regiões endêmicas de malária, os condicionantes de saúde não são contemplados de forma sistemática nos processos de licenciamento ambiental, não atendendo integralmente aos princípios da promoção da saúde e da sustentabilidade socioambiental.

Dessa forma, o problema só será resolvido com a inclusão, por meio de normas e leis específicas, dos aspectos de saúde como condicionantes a serem observados no processo de licenciamento ambiental, desde a elaboração do Termo de Referência que irá orientar os Estudos de Impacto Ambiental e o respectivo Relatório de Impacto Ambiental, documentos que embasam a análise da viabilidade ambiental de um projeto, da necessidade e do tipo de medidas mitigadoras que deverão ser adotadas. 


\section{Referências bibliográficas}

BARBOSA, E. M.; BARATA, M. M. de L.; HACON, S. de S.. A saúde no licenciamento ambiental: uma proposta metodológica para a avaliação dos impactos da indústria de petróleo e gás. Ciência e saúde coletiva, Rio de Janeiro, v.17, n.2, p. 299-310, 2012. Disponível em http://www.scielo.br/pdf/csc/v17n2/a05v17n2.pdf. Acesso: 15 ago. 2014.

BRASIL. Lei n. 6.938 , de 31 de agosto de 1981. Dispõe sobre a Política Nacional do Meio Ambiente, seus fins e mecanismos de formulação e aplicação, e dá outras providências. Diário Oficial da República Federativa do Brasil, Brasília, DF, 2 set 1981. Disponível em http://www.planalto.gov.br/ccivil 03/leis/L6938.htm. Acesso em: 30 set. 2014.

BRASIL. Lei $n .^{\circ} 11.516$, de 28 de agosto de 2007. Dispõe sobre a criação do Instituto Chico Mendes de Conservação da Biodiversidade - Instituto Chico Mendes; altera as Leis $\mathrm{n}^{\text {os }} 7.735$, de 22 de fevereiro de 1989, 11.284, de 2 de março de 2006, 9.985, de 18 de julho de 2000, 10.410, de 11 de janeiro de 2002, 11.156, de 29 de julho de 2005, 11.357, de 19 de outubro de 2006, e 7.957, de 20 de dezembro de 1989; revoga dispositivos da Lei no 8.028, de 12 de abril de 1990, e da Medida Provisória no 2.216-37, de 31 de agosto de 2001; e dá outras providências. Diário Oficial da República Federativa do Brasil, Brasília, DF, 28 ago. $2007 \quad$ Edição $\quad$ Extra. Disponível em http://www.planalto.gov.br/ccivil 03/ ato2007-2010/2007/lei/l11516.htm. Acesso em: 30 set. 2014.

BRASIL. Decreto n. 0 99.274, de 6 de junho de 1990. Regulamenta a Lei no 6.902, de 27 de abril de 1981, e a Lei ํㅜ 6.938, de 31 de agosto de 1981, que dispõem, respectivamente sobre a criação de Estações Ecológicas e Áreas de Proteção Ambiental e sobre a Política Nacional do Meio Ambiente, e dá outras providências. Diário Oficial da República Federativa do Brasil, Brasília, DF, 7 jun. 1990. Disponível em http://www.planalto.gov.br/ccivil 03/decreto/antigos/d99274.htm. Acesso em: 30 set. 2014.

BRASIL. Constituição da República Federativa do Brasil 1988. Disponível em http://www.planalto.gov.br/ccivil 03/constituicao/ConstituicaoCompilado.htm. Acesso em: 15 ago. 2014.

BRASIL. Resolução CONAMA $n . \stackrel{0}{1}$, de 23 de janeiro de 1986. Dispõe sobre critérios básicos e diretrizes gerais para a avaliação de impacto ambiental. Diário Oficial da República Federativa do Brasil, Brasília, DF, 17 fev. 1986. Disponível em http://www.mma.gov.br/port/CONAMA/legiabre.cfm?codlegi=23. Acesso em: 30 set. 2014.

BRASIL. Resolução CONAMA n. 237, de 22 de dezembro de 1997. Regulamenta os aspectos de licenciamento ambiental estabelecidos na Política Nacional do Meio Ambiente. Diário Oficial da República Federativa do Brasil, Brasília, DF, 22 dez. 1997. Disponível em http://www.mma.gov.br/port/CONAMA/legiabre.cfm?codlegi=237. Acesso em: 30 set. 2014.

BRASIL. Resolução CONAMA n. ${ }^{-286,} 30$ de agosto de 2001. Dispõe sobre 0 licenciamento ambiental de empreendimentos nas regiões endêmicas de malária. Diário Oficial da República Federativa do Brasil, Brasília, DF, 17 dez. 2001. Disponível em http://www.mma.gov.br/port/CONAMA/legiabre.cfm?codlegi=283. Acesso em: 30 set. 2014. 
BRASIL. Portaria SVS/MS no 1, de 13 de janeiro de 2014. Estabelece diretrizes, procedimentos, fluxos e competência para obtenção do Laudo de Avaliação do Potencial Malarígeno (LAPM) e do Atestado de Condição Sanitária (ATCS) de projetos de assentamento de reforma agrária e outros empreendimentos sujeitos ao licenciamento ambiental em áreas de risco ou endêmica para malária. Diário Oficial da República Federativa do Brasil, Brasília, DF. Disponível em http://bvsms.saude.gov.br/bvs/saudelegis/svs/2014/prt0001 1301 2014.html. Acesso em: 30 set 2014.

BRASIL. Portaria Interministerial 419, de 26 de outubro de 2011. Regulamenta a ação dos órgãos e entidades da Administração Pública Federal envolvidos no licenciamento ambiental, de que trata o art. 14 da Lei $n .011 .516$, de 28 de agosto de 2007. Diário Oficial da República Federativa do Brasil, Brasília, DF, 28 out. 2011. Disponível em < http://pesquisa.in.gov.br/imprensa/jsp/visualiza/index.jsp?jornal=1\&pagina=81\&data=28/10/ 2011. Acesso em: 30 set 2014.

BRASIL. Ministério da Saúde. Secretaria de Vigilância em Saúde. Departamento de Vigilância em Saúde Ambiental e Saúde do Trabalhador. Avaliação de Impacto à Saúde AIS: metodologia adaptada para aplicação no Brasil. Brasília, Ministério da Saúde, 2014.

MILARÉ, E. Direito do ambiente: a gestão ambiental em foco: doutrina, jurisprudência, glossário. São Paulo: Revista dos Tribunais, 2009. 1343 p.

RIGOTTO, R. M. Inserção da saúde nos estudos de impacto ambiental: o caso de uma termelétrica a carvão mineral no Ceará. Ciência e saúde coletiva, Rio de Janeiro, v. 14, n.6, p. 2049-2059, 2009. Disponível em http://www.scielo.br/pdf/csc/v14n6/12.pdf. Acesso em: 15 ago. 2014.

SILVEIRA, M.; ARAÚJO NETO, M. D. de. Licenciamento ambiental de grandes empreendimentos: conexão possível entre saúde e meio ambiente. Ciência e saúde coletiva, Rio de Janeiro, v. 19, n.9, set 2014. Disponível em http://www.scielo.br/scielo.php?script=sci arttext\&pid=S141381232014000903829\&lang=pt. Acesso em: 15 ago. 2014.

SILVEIRA, M. [et al]. Perspectiva da avaliação de impacto à saúde nos projetos de desenvolvimento no Brasil: importância estratégica para a sustentabilidade. Cadernos de Saúde Coletiva, Rio de Janeiro, v. 20, n.1, p.57-63, 2012. Disponível em http://www.cadernos.iesc.ufri.br/cadernos/images/csc/2012 1/artigos/CSC v20n1 5763.pdf. Acesso em: 15 ago. 2014.

TAMBELLINI, A. T.; CÂMARA, V.de M. A temática saúde e ambiente no processo de desenvolvimento do campo da saúde coletiva: aspectos históricos, conceituais e metodológicos. Ciência e saúde coletiva, Rio de Janeiro, v.3, n.2, 1998. Disponível em http://www.scielosp.org/scielo.php?script=sci arttext\&pid=S141381231998000200005\&lang=pt. Acesso em: 15 ago. 2014. 